\title{
Influence of demographic factors and serotonin transporter-linked polymorphic region (5-HTTLPR) variants on major depression in a northeastern Thai population
}

\author{
Tewin Tencomnao ${ }^{\mathrm{a}}$, Thapanut Sritharathikhun ${ }^{\mathrm{b}}$, Sarawut Suttirat ${ }^{\mathrm{c}}$ \\ ${ }^{a}$ Center for Excellence in Omics-Nano Medical Technology Development Project, Department of \\ Clinical Chemistry, Faculty of Allied Health Sciences, Chulalongkorn University, Bangkok 10330; \\ ${ }^{b}$ Loei Rajanagarindra Psychiatric Hospital, Loei 42000; ' Faculty of Medical Technology, Huachiew \\ Chalermprakiet University, Samuth Prakarn 10540, Thailand
}

\begin{abstract}
Background: Several lines of evidence suggest that the serotonergic system may be involved in the etiology of major depressive disorder (MDD).

Objective: Investigate a potential association between the functional polymorphism in the serotonin transporter-linked polymorphic region (5-HTTLPR) and MDD in a northeastern Thai population, and explore the involvement of demographic characteristics in this disorder.

Methods: One hundred eighty seven patients with MDD and 207 healthy controls were recruited from the same geographical area into the study. The 5-HTTLPR genotypes were determined using polymerase chain reaction (PCR) and analyzed statically.

Results: Significant demographic differences between the two groups were observed, which included age, marital status, occupation, educational background, income, and alcohol use. The allele frequencies of the 5HTTLPR polymorphism in our studied population were relatively near those of Asian populations, especially Chinese, which was regarded as enormously distinct from those of Caucasians. Nevertheless, our present study found no significant association between this polymorphism and MDD with respect to either genotype distributions or allele frequencies.

Conclusion: No involvement of the 5-HTTLPR polymorphism was suggested, but demographic features in MDD were highlighted with respect to this studied population.
\end{abstract}

Keywords: 5-HTTLPR, association study, demographic data, genetic polymorphism, major depressive disorder, Thai population

Major depressive disorder (MDD) is one of the most urgent public health issues. It is associated with significant disability with the high lifetime prevalence of approximately $15 \%$ [1]. MDD is projected to be the first leading cause in high-income countries for

Correspondence to: Tewin Tencomnao, $\mathrm{PhD}$, Center for Excellence in Omics-Nano Medical Technology Development Project, Department of Clinical Chemistry, Faculty of Allied Health Sciences, Chulalongkorn University, Bangkok 10330, Thailand.E-mail: tewin.t@chula.ac.th disability-adjusted life years (DALY) in 2030 [2]. Both genetic and environmental factors are acknowledged to significantly modify the risk for MDD. In particular, the estimated heritability of MDD is $35-40 \%[3,4]$. Candidate gene studies attempted to identify genetic MDD risk factors have reported inconsistent results. However, since genetic polymorphisms are distinct due to ethnicities, various relevant DNA sequence variations in promising candidate genes involved in the susceptibility to MDD remain to be elucidated in each population. 
The serotonergic system, which consists of serotonin (5-HT)-producing cells, 5-HT transporters (5-HTT) and 5-HT receptors (5-HTR), may be traitdependent and associated with disturbances in the regulation of MDD [5]. Therefore, polymorphisms of the main serotonergic genes have been received considerable attention, particularly those of 5-HTT. To date, most well-characterized and extensively studied polymorphism in the 5-HTT gene is a 44-base pair (bp) insertion/deletion in the promoter region that is termed the functional 5-HTT gene-linked polymorphic region (5-HTTLPR) [6, 7]. With respect to its functional significance, the long (1) allele of 5-HTTLPR has been shown to generate higher transcriptional activity than the short (s) allele in many cells [7-9]. Consistently, lower serotonin reuptake from the synaptic cleft in s-allele carriers compared with patients homozygous for the 1-allele [10]. The transcriptional efficiency addressed in this regard is physiologically critical. It affects mood tone, circadian, and neuroendocrine functions such as sleep, appetite, sexual behavior, and motor function [11]. These features are frequently disturbed in MDD.

Previous research indicates that the 5-HTTLPR polymorphism might be related with MDD. Many groups have reported positive associations [12-19], while certain groups have revealed negative results [20-25]. Ethnic differences may be a reason for these conflicting data. In fact, the 5-HTTLPR s-allele has been experimentally proven as the minor allele for Caucasians, but as a major one for Asians [26, 27]. Of particular interest, based on studies of Asian populations, the 5-HTTLPR polymorphism is associated with MDD in Chinese [18, 19], but not in Japanese [20, 21] and Korean [22, 25]. In the nature of population genetic characteristics, correlations between the Chinese and all regional Thai populations is higher than those between the Japanese and Thai populations [28]. Therefore, there is potential for an association between the 5-HTTLPR polymorphism and MDD in Thai population. Nevertheless, the two Chinese studies with positive associations gave contradicting results. In fact, the 5-HTTLPR s-allele was the risk allele for one study [18], while the 1-allele was the risk one for the other [19].

The genetic association between this particular functional polymorphisms and MDD has never been analyzed in any part of Thai populations. In this study, we made a case-control study design to investigate the possible association in a northeastern Thai population. In addition, we studied demographic characteristics of cases and controls since these potential contributing factors have not been examined in this population yet.

\section{Materials and methods Subjects}

Participants recruited for this study were 187 unrelated patients with MDD (aged 44.9 \pm 12.9 years) and 207 unrelated healthy controls (aged 41.3-9.8 years). In our recruiting process, we intended to have both groups matched for gender. The MDD subjects were diagnosed according to DSM-IV criteria [29] by experienced psychiatrists. The two groups permanently resided in the same geographic region.

This study was approved by the Ethics Local Committee of Medical Experiments on Human Subjects. The written informed consent was given by all participants.

\section{DNA extraction}

Genomic DNA samples were isolated from whole blood using FlexiGene DNA kit (Qiagen GmbH, Hilden, Germany).

\section{Determination of the 5-HTTLPR polymorphism}

Genotyping of the 5-HTTLPR polymorphism was performed by polymerase chain reaction (PCR), using Taq PCRx DNA polymerase (Invitrogen, Carlsbad, USA) and previously reported primer sequences specific to the 5-HTTLPR (forward primer: 5'GGCGTTGCCGCTCTGAATTGC-3' and reverse primer: 5'-GAGGGACTGAGCTGGACAACCAC$3^{\prime}$ ') [7]. Briefly, PCR amplification was carried out in a final volume of $25 \mu \mathrm{L}$ consisting of genomic DNA as a template, $0.2 \mathrm{mM}$ each deoxyribonucleotide, 0.2 $\mu \mathrm{M}$ of forward and reverse primers, $2 \mathrm{X}$ PCRx enhancer solution, $20 \mathrm{mM}$ Tris- $\mathrm{HCl}(\mathrm{pH} 8.4), 50 \mathrm{mM}$ $\mathrm{KCl}, 1.5 \mathrm{mM} \mathrm{MgSO}_{4}$ and $1.25 \mathrm{U}$ of Taq DNA polymerase. After denaturing for two minutes at $95^{\circ} \mathrm{C}$, the desired DNA fragment was amplified for 35 cycles of $95^{\circ} \mathrm{C}$ for 30 seconds, $60^{\circ} \mathrm{C}$ for 30 seconds, and $68^{\circ} \mathrm{C}$ for one minute with the final extension at $68^{\circ} \mathrm{C}$ for 10 minutes. PCR products along with $100 \mathrm{bp}$ DNA ladder (New England Biolabs, Beverly, USA) were electrophored on $3.5 \%$ agarose gel and visualized by ethidium bromide staining. Amplification of the 5-HTTLPR resulted in five alleles differing by $44 \mathrm{bp}$ $(14,16,18,20$, and 22 copies of a repetitive sequence comprising a GC-rich 20-23 bp repeat element) as 
previously reported [22]. Randomly-selected DNA samples were subjected to direct sequencing to validate the genotypes. The first two allelic types were predominant, thus designating them as s and 1 for 14 and 16 copies, respectively. Since the last three allelic types known as extra long (xl) alleles were rarely found, they were included in 1 allele for statistical analysis.

\section{Statistical analysis}

For their demographic features, they were compared by Chi-square $\left(\chi^{2}\right)$ tests using GraphPad Prism 5 software. Hardy-Weinberg equilibrium (HWE) for the distributions of genotypes was estimated by the $\chi^{2}$ tests. Allele and genotype frequencies were compared between groups using the $\chi^{2}$ tests with Yates correction. Odds ratios (OR) with $95 \%$ confidence interval (CI) were calculated using EpiCalc 2000 version 1.02 (http:// www.brixtonhealth.com/epicalc.html). A p-value of $<0.05$ was considered significant.

\section{Results \\ Demographic characteristics of the studied population}

Characteristics of major depressive and healthy control subjects were compared with regard to various demographic factors as shown in Table 1. Significant differences between the two groups were observed with regard to age $(p=0.003)$, marital status $(\mathrm{p}=0.047)$, occupation $(\mathrm{p}<0.0001)$, educational background $(p<0.0001)$, income $(p<0.0001)$, and alcohol use $(\mathrm{p}=0.021)$, thus highlighting the impact of these demographic factors in the involvement of MDD in our studied population.

Table 1. Demographic characteristics and descriptive statistics of the studied population.

\begin{tabular}{|c|c|c|c|c|c|}
\hline Psychosocial factors & Controls (\%) & MDD (\%) & $\mathbf{N}(\%)$ & $\chi^{2}, \mathrm{df}$ & P-value \\
\hline \multicolumn{6}{|l|}{ Gender } \\
\hline male & $78(37.68)$ & $65(34.76)$ & $143(36.29)$ & & \\
\hline female & $129(62.32)$ & $122(65.24)$ & $251(63.71)$ & & \\
\hline total & $207(100)$ & $187(100)$ & $394(100)$ & $0.36,1$ & $0.547^{\mathrm{a}}$ \\
\hline \multicolumn{6}{|l|}{ Age (years) } \\
\hline $10-20$ & $3(1.45)$ & $6(3.23)$ & $9(2.29)$ & & \\
\hline $21-30$ & $25(12.08)$ & $21(11.29)$ & $46(11.70)$ & & \\
\hline $31-40$ & $72(35.75)$ & $45(24.19)$ & $117(29.77)$ & & \\
\hline $41-50$ & $74(34.78)$ & $52(27.96)$ & $126(32.06)$ & & \\
\hline $51-60$ & $25(12.08)$ & $39(20.97)$ & $64(16.28)$ & & \\
\hline$>60$ & $8(3.86)$ & $23(12.37)$ & $31(7.89)$ & & \\
\hline total & $207(100)$ & $186(100)$ & $393(100)$ & $23.58,5$ & $0.003^{b}$ \\
\hline \multicolumn{6}{|l|}{ Marital status } \\
\hline single & $32(15.46)$ & $27(14.44)$ & $59(14.97)$ & & \\
\hline married & $163(78.74)$ & $133(71.12)$ & $296(75.13)$ & & \\
\hline divorced & $8(3.86)$ & $12(6.42)$ & $20(5.08)$ & & \\
\hline separated & $2(0.97)$ & $8(4.28)$ & $10(2.54)$ & & \\
\hline widowed & $2(0.97)$ & $7(3.74)$ & $9(2.28)$ & & \\
\hline total & $207(100)$ & $187(100)$ & $394(100)$ & $9.65,4$ & $0.047^{\mathrm{b}}$ \\
\hline \multicolumn{6}{|l|}{ Occupation } \\
\hline wageworker & $52(25.12)$ & $13(7.07)$ & $65(16.62)$ & & \\
\hline trader & $11(5.31)$ & $9(4.89)$ & $20(5.12)$ & & \\
\hline government official & $31(14.98)$ & $8(4.35)$ & $39(9.97)$ & & \\
\hline company employee & $5(2.42)$ & $1(0.54)$ & $6(1.53)$ & & \\
\hline student & $3(1.45)$ & $2(1.09)$ & $5(1.28)$ & & \\
\hline agriculture & $77(37.20)$ & $119(64.67)$ & $196(50.13)$ & & \\
\hline others & $28(13.53)$ & $32(17.39)$ & $60(15.35)$ & & \\
\hline total & $207(100)$ & $184(100)$ & $391(100)$ & $48.11,6$ & $<0.0001^{\mathrm{b}}$ \\
\hline
\end{tabular}


Table 1. Demographic characteristics and descriptive statistics of the studied population (Continued).

\begin{tabular}{|c|c|c|c|c|c|}
\hline Psychosocial factors & Controls (\%) & MDD (\%) & $\mathbf{N}(\%)$ & $\chi^{2}, \mathrm{df}$ & P-value \\
\hline \multicolumn{6}{|l|}{ Education background } \\
\hline lower than primary & $2(0.99)$ & $12(7.23)$ & $14(3.61)$ & & \\
\hline primary & $96(47.52)$ & $113(68.07)$ & $229(59.02)$ & & \\
\hline lower secondary & $18(8.91)$ & $14(8.43)$ & $32(8.25)$ & & \\
\hline higher secondary & $35(17.33)$ & $15(9.04)$ & $50(12.89)$ & & \\
\hline vocational/technical & $26(12.87)$ & $9(5.42)$ & $35(9.02)$ & & \\
\hline bachelor degree & $25(12.38)$ & $2(1.20)$ & $27(6.96)$ & & \\
\hline higher than bachelor degree & $0(0.00)$ & $1(0.60)$ & $1(0.26)$ & & \\
\hline total & $202(100)$ & $186(100)$ & $388(100)$ & $42.76,6$ & $<0.0001^{\mathrm{b}}$ \\
\hline \multicolumn{6}{|l|}{ Monthly income (Baht) } \\
\hline$<5,000$ & $85(41.26)$ & $137(73.26)$ & $222(56.49)$ & & \\
\hline $5,000-10,000$ & $72(34.95)$ & $23(12.30)$ & $95(24.17)$ & & \\
\hline $10,001-20,000$ & $28(13.59)$ & $17(9.09)$ & $45(11.45)$ & & \\
\hline$>20,000$ & $21(10.19)$ & $10(5.35)$ & $31(7.89)$ & & \\
\hline total & $206(100)$ & $187(100)$ & $393(100)$ & $43.23,3$ & $<0.0001^{\mathrm{b}}$ \\
\hline \multicolumn{6}{|l|}{ Smoking consumption } \\
\hline smoker & $30(14.56)$ & $36(19.25)$ & $66(16.79)$ & & \\
\hline nonsmoker & $176(85.44)$ & $151(80.75)$ & $327(83.21)$ & & \\
\hline total & $206(100)$ & $187(100)$ & $393(100)$ & $1.54,1$ & 0.214 \\
\hline \multicolumn{6}{|l|}{ Alcohol consumption } \\
\hline drinker & $59(28.64)$ & $35(18.72)$ & $94(23.92)$ & & \\
\hline nondrinker & $147(71.36)$ & $152(81.28)$ & $299(76.08)$ & & \\
\hline total & $206(100)$ & $187(100)$ & $393(100)$ & $5.31,1$ & $0.021^{\mathrm{b}}$ \\
\hline
\end{tabular}

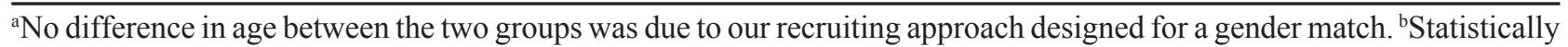
significant $(\mathrm{p}<0.05)$.

\section{Association between the 5-HTTLPR polymorphism and MDD}

One hundred eighty seven patients with MDD and 194 healthy controls were successfully genotyped for the 5-HTTLPR polymorphism. The genotype distributions and allele frequencies of the 5-HTTLPR polymorphism were successfully determined as shown in Table 2. The genotype distributions of this particular polymorphism were in HWE for both patients with MDD $(p=0.679)$ and healthy controls $(p=0.189)$. No significant difference was found between the two groups for either genotype distributions $\left(\chi^{2}=1.42\right.$, df $=2, \mathrm{p}=0.491)$ or allele frequencies $\left(\chi^{2}=0.90, \mathrm{df}=1\right.$, $\mathrm{p}=0.343, \mathrm{OR}=1.18[95 \% \mathrm{CI}=0.86-1.61])$ of the 5HTTLPR polymorphism.

Table 2. Genotype distributions and allele frequencies of the 5-HTTLPR polymorphism in patients with MDD and controls.

\begin{tabular}{cccccc}
\hline Variables & $\begin{array}{c}\text { MDD } \\
\text { N=187 (\%) }\end{array}$ & $\begin{array}{c}\text { Controls } \\
\mathbf{N}=\mathbf{1 9 4}(\mathbf{\%})\end{array}$ & $\boldsymbol{\chi}^{\mathbf{2}}, \mathbf{d f}$ & P-value & OR (95\%CI) \\
\hline $\begin{array}{c}\text { Genotype } \\
\text { SS }\end{array}$ & $101(54.01)$ & $99(51.03)$ & $1.42,2$ & 0.491 & - \\
sl & $69(36.90)$ & $70(36.08)$ & & & \\
ll & $17(9.09)$ & $25(12.89)$ & & & \\
Allele & $271(72.46)$ & $268(69.07)$ & & & \\
S & $103(27.54)$ & $120(30.93)$ & & & \\
1 & & & & & \\
\hline
\end{tabular}




\section{Discussion}

In the present investigation, the impacts of demographic features on MDD were emphasized because MDD is linked with socioeconomic status of the patients (or their quality of life). In our view-points, demographics could answer the causes and outcomes of MDD clearly. The present result indicates the importance of demographic factors in MDD. This was in agreement with previous reports by different research groups worldwide [30-32]. It is to be noted that these demographic factors have been proven to have varying degrees of contributions in this regard.

In the present study, there was no difference in gender between the two groups. This is owing to our designed gender-matching. If we randomly collected the participants, the ratio of female to male patients would be high. In fact, mood disorders such as MDD have been reported to be more common in women [33].

Difference in age between the two groups was obvious, because proportions of 30's and 40's years old increased in the control group, while proportions of 50's and 60's were somewhat elevated. This highlights the role of aging in MDD. In fact, the observed difference in age between the two groups may affect the outcome of an association test. For instance, certain healthy controls may become ill because of MDD in the future. Although proportions of 50's and 60's were elevated in the patient group, we did not know the number of patients with MDD with younger age of onset.

As far as the marital status was concerned, the patient group with unhealthy families (divorced, separated or widowed) was approximately three-fold higher than those of the control group.

For their occupation, most of the participants (about 50\%) were agricultural professionals. However, participants with agricultural careers were almost twofold higher in the patients compared to the controls. Others reported in this category were the nonresponders and unemployed people. Regarding their educational background, the majority of subjects (about $60 \%$ ) graduated from the primary school. Nevertheless, the control group graduated with higher levels than those in the patient group.

In analyzing their income, the majority of patients (about $73 \%$ ) gained less than 5,000 Baht a month, whereas the majority of controls (almost 60\%) received at least 5,000 Baht a month. Therefore, these three factors (occupation, education, and income) seemed to be considerably involved in MDD.

With respect to unhealthy coping skills, we examined if consumption of either tobacco or alcohol was involved in MDD in this studied population. Alcohol use was about 1.5-fold higher in the patient group compared to the control group, thereby signifying the connection between alcohol and MDD. There was no difference in smoking consumption between the two groups, where smokers were approximately $14 \%$ and $19 \%$ in the control group and the patient group, respectively. These numbers were indeed comparable to the smoking prevalence rate in Thailand, which has gradually decreased over the past ten years to roughly $15 \%$ in 2006 [34]. This finding was not surprising because the association between smoking and MDD was very small to undetectable worldwide [35-37]. Possibly, this may be due to the tobacco control policy globally.

Notably, global variations in the allelic frequencies of the 5-HTTLPR polymorphism have been recognized among European, European American, African American, Japanese, native-Americans, Chinese, and African populations [26, 27]. Distinct results will be revealed by association studies in distinct ethnic populations. Our current study aimed at investigating a potential association between 5-HTTLPR polymorphism and MDD. Regarding the allele frequencies of this polymorphism, the 5-HTTLPR 1 allele was established as the minor allele frequency of roughly $30 \%$, which was close to that of Asian populations, especially Chinese, thereby being in agreement with the preceding findings [26, 27]. We found no association between this polymorphism and MDD. According to a recent meta-analysis comprising 22 articles [27], the SS genotype was significantly associated with an increased risk of MDD among Caucasian populations, but no significant association was found among the Asians. This supports our current finding.

Many studies reported discrepancy in their association results. This would be caused by not only ethnic difference, but also other factors such as limited sample sizes, ethnic heterogeneity, and environmental factors. In our investigation, the samples were recruited from single, homogeneous populations. Both patients and controls were of the northeastern Thai group and recruited from the same geographical area. Our study did not positively detect any association between 5-HTTLPR polymorphism and MDD. This did not rule out the possibility of either gene-by-gene 
or gene-by-environment interactions. This is because this particular polymorphism plays a role in modifying the risk of MDD when interacting with other factors $[18,19,25,26,38]$. Nevertheless, if determination of interaction effects is of particular interest for further investigations, enlarged sample size is needed for this regard. It should be noted that genetic association studies are required to be carried out with highest precautions since errors can be possible as previously addressed by this laboratory $[39,40]$.

In conclusion, many demographic factors including age, marital status, occupation, educational background, income, and alcohol consumption were associated with MDD in this studied population, whereas the effect of 5-HTTLPR polymorphism was not found.

\section{Acknowledgments}

This study was financially supported by the National Research Council of Thailand (NRCT) and the Chulalongkorn University Centenary Academic Development Project. We are indebted to Mr. Anont Laorngnual and Mr. Atipong Kitprasert for their assistance in blood collection. We also wish to express our gratitude to Ms. Anchalee Prasansuklab and Ms. Varaporn Rakkhitawatthana for their help in laboratory work and statistical analysis. The authors have no conflict of interest to report.

\section{References}

1. Moussavi S, Chatterji S, Verdes E, Tandon A, Patel V, Ustun B. Depression, chronic diseases, and decrements in health: results from the World Health Surveys. Lancet. 2007; 370:851-8.

2. Mathers C, Loncar D. Projections of global mortality and burden of disease from 2002 to 2030. PLOS Med. 2006;3:e442.

3. Sullivan PF, Neale MC, Kendler KS. Genetic epidemiology of major depression: review and metaanalysis. Am J Psychiatry. 2000; 157:1552-62.

4. Shih RA, Belmonte PL, Zandi PP. A review of the evidence from family, twin and adoption studies for a genetic contribution to adult psychiatric disorders. Int Rev Psychiatry. 2004; 16:260-83.

5. Craddock N, Davé S, Greening J. Association studies of bipolar disorder. Bipolar Disord. 2001; 3:284-98.

6. Lesch KP, Balling U, Gross J, Strauss K, Wolozin BL, Murphy DL, et al. Organization of the human serotonin transporter gene. J Neural Transm Gen Sect. 1994; n95: $157-62$.
7. Heils A, Teufel A, Petri S, Stöber G, Riederer P, Bengel $\mathrm{D}$, et al.Allelic variation of human serotonin transporter gene expression. J Neurochem. 1996; 66:2621-4.

8. Lesch KP, Bengel D, Heils A, Sabol SZ, Greenberg $\mathrm{BD}$, Petri S, et al. Association of anxiety-related traits with a polymorphism in the serotonin transporter gene regulatory region. Science. 1996; 274:1527-31.

9. Mortensen OV, Thomassen M, Larsen MB. Functional analysis of a novel human serotonin transporter gene promoter in immortalized raphe cells. Brain Res Mol Brain Res. 1999; 68:141-8.

10. Collier DA, Stober G, Li T, Heils A, Catalano M, Di BD, et al. A novel functional polymorphism within the promoter of the serotonin transporter gene: possible role in susceptibility to affective disorders. Mol Psychiatry. 1996; 1:453-60.

11. Lesch KP, Mossner R. Genetically driven variation in serotonin uptake: is there a link to affective spectrum, neurodevelopmental, and neurodegenerative disorders? Biol Psychiatry. 1998; 44:179-92.

12. Joiner TEJr, Johnson F, Soderstrom K, Brown JS. Is there an association between serotonin transporter gene polymorphism and family history of depression? J Affect Disord. 2003; 77: 273-5.

13. Nobile M, Cataldo MG, Giorda R, Battaglia M, Baschirotto C, Bellina M, et al. A case-control and family-based association study of the 5-HTTLPR in pediatric-onset depressive disorders. Biol Psychiatry. 2004; 56:292-5.

14. Hoefgen B, Schulze TG, Ohlraun S, von Widdern O, Höfels S, Gross M, et al. The power of sample size and homogenous sampling: association between the 5-HTTLPR serotonin transporter polymorphism and major depressive disorder. Biol Psychiatry. 2005; 57:247-51.

15. Gonda X, Juhasz G, Laszik A, Rihmer Z, Bagdy G. Subthreshold depression is linked to the functional polymorphism of the 5HT transporter gene. J Affect Disord. 2005; 87:291-7.

16. Cervilla JA, Rivera M, Molina E, Torres-Gonzalez F, Bellon JA, Moreno B, et al. The 5-HTTLPR s/s genotype at the serotonin transporter gene (SLC6A4) increases the risk for depression in a large cohort of primary care attendees: the PREDICT-gene study. Am J Med Genet B Neuropsychiatr Genet. 2006; 141: 912-7.

17. Dick DM, Plunkett J, Hamlin D, Nurnberger JJr, Kuperman S, Schuckit M, et al. Association analyses of the serotonin transporter gene with lifetime depression and alcohol dependence in the 
Collaborative Study on the Genetics of Alcoholism (COGA) sample. Psychiatr Genet. 2007; 17:8-35.

18. Cao MQ, Hu SY, Zhang CH, Xia DS. Study on the interrelationship between 5-HTTLPR/G-protein beta3 subunit (C825T) polymorphisms and depressive disorder. Psychiatr Genet. 2007; 17:233-8.

19. Zhang K, Xu Q, Xu Y, Yang H, Luo J, Sun Y, et al. The combined effects of the 5-HTTLPR and 5-HTR1A genes modulates the relationship between negative life events and major depressive disorder in a Chinese population. J Affect Disord. 2009; 114:224-31.

20. Kunugi H, Hattori M, Kato T, Tatsumi M, Sakai T, Sasaki T, et al. Serotonin transporter gene polymorphisms: ethnic difference and possible association with bipolar affective disorder. Mol Psychiatry. 1997; 2:457-62.

21. Ohara K, Nagai M, Tsukamoto T, Tani K, Suzuki Y, Ohara K. Functional polymorphism in the serotonin transporter promoter at the SLC6A4 locus and mood disorders. Biol Psychiatry. 1998; 44:550-4.

22. Kim DK, Lim SW, Lee S, Sohn SE, Kim S, Hahn CG, et al. Serotonin transporter gene polymorphism and antidepressant response. Neuroreport. 2000; 11:215-9.

23. Mendlewicz J, Massat I, Souery D, Del-Favero J, Oruc L, Nothen MM, et al. Serotonin transporter 5HTTLPR polymorphism and affective disorders: no evidence of association in a large European multicenter study. Eur J Hum Genet. 2004; 12:377-82.

24. Willis-Owen SA, Turri MG, Munafò MR, Surtees PG, Wainwright NW, Brixey RD, et al. The serotonin transporter length polymorphism, neuroticism, and depression: a comprehensive assessment of association. Biol Psychiatry. 2005; 58:451-6.

25. Kim JM, Stewart R, Kim SW, Yang SJ, Shin IS, Kim YH, et al. Interactions between life stressors and susceptibility genes (5-HTTLPR and BDNF) on depression in Korean elders. Biol Psychiatry. 2007; 62: 423-8.

26. Kiyohara C, Yoshimasu K. Molecular epidemiology of major depressive disorder. Environ Health Prev Med. 2009; 14:71-87.

27. Kiyohara C, Yoshimasu K. Association between major depressive disorder and a functional polymorphism of the 5-hydroxytryptamine (serotonin) transporter gene: a meta-analysis. Psychiatr Genet. 2010; 20:49-58.

28. Mahasirimongkol S, Chantratita W, Promso S, Pasomsab E, Jinawath N, Jongjaroenprasert W, et al. Similarity of the allele frequency and linkage disequilibrium pattern of single nucleotide polymorphisms in drug-related gene loci between Thai and northern East Asian populations: implications for tagging SNP selection in Thais. J Hum Genet. 2006; 51:896-904.

29. American Psychiatric Association. Diagnostic and statistical manual of mental disorders. 4th ed. Washington DC:American Psychiatric Association, 1994.

30. Cooke DJ. Depression: demographic factors in the distribution of different syndromes in the general population. Soc Psychiatry. 1982; 17:29-36.

31. Rifel J, Svab I, Ster MP, Pavlic DR, King M, Nazareth I. Impact of demographic factors on recognition of persons with depression and anxiety in primary care in Slovenia. BMC Psychiatry. 2008; 8:96.

32. Li N, Zhang J. Influencing factors for depression among Chinese suicide survivors. Psychiatry Res. 2010; 178:97-100.

33. Currier D, Mann MJ, Oquendo MA, Galfalvy H, Mann JJ. Sex differences in the familial transmission of mood disorders. J Affect Disord. 2006; 95:51-60.

34. Leartsakulpanitch J, Nganthavee W, Salole E. The economic burden of smoking-related disease in Thailand: a prevalence-based analysis. J Med Assoc Thai. 2007; 90:1925-9.

35. Sheikh K. Depression and the association of smoking and suicide. Am J Public Health. 2000; 90:1952-3.

36. Murphy JM, Horton NJ, Monson RR, Laird NM, Sobol AM, Leighton AH. Cigarette smoking in relation to depression: historical trends from the Stirling County Study. Am J Psychiatry. 2003; 160:1663-9.

37. Johnson EO, Breslau N. Is the association of smoking and depression a recent phenomenon? Nicotine Tob Res. 2006; 8:257-62.

38. Risch N, Herrell R, Lehner T, Liang KY, Eaves L, Hoh $\mathrm{J}$, et al. Interaction between the serotonin transporter gene (5-HTTLPR), stressful life events, and risk of depression: a meta-analysis. JAMA. 2009; 301:2462-71. Erratum 302:492.

39. Tencomnao T, Boonmalert R. Misgenotyping of dopamine receptor D1 gene-48A/G polymorphism. Am J Med Genet B Neuropsychiatr Genet. 2009; 150B:447-9.

40. Tencomnao T. Interaction of serotonin-related genes affects short-term antidepressant response in major depressive disorder. Prog Neuropsychopharmacol Biol Psychiatry. 2010; 34:432. 